ORIGINAL ARTICLE

\title{
A questionnaire survey of stress and bullying in doctors undertaking research
}

\author{
J Stebbing, S Mandalia, S Portsmouth, P Leonard, J Crane, M Bower, H Earl, L Quine
}

Postgrad Med J 2004;80:93-96. doi: 10.1136/pmj.2003.009001

See end of article for authors' affiliations

Correspondence to:

Dr Justin Stebbing,

Department of

Immunology, Chelsea and

Westminster Hospital, 369

Fulham Road, London

SW10 9NH, UK:

i.stebbing@imperial.ac.uk

Submitted 16 April 2003

Accepted 5 August 2003
Background: Research is an increasingly important aspect of higher medical training for many doctors. Studies investigating sources of stress, isolation, and workplace bullying have not previously sought information in this setting.

Methods: An internet based questionnaire survey of doctors undertaking research $(n=259)$ was conducted to examine stressors and levels of job satisfaction in this potentially vulnerable group. In order to assess overall levels of satisfaction, we asked whether doctors would recommend their research post to a colleague.

Results: There was a statistically significant association between those who would not recommend their post to a colleague and those who had difficulties in arranging funding and in writing up $(p<0.001)$. Further significant correlations were found between dissatisfaction with the post and lack of help, support, and advice from supervisors and colleagues, wanting to change supervisors, experience of the major categories of workplace bullying, and having an inadequate clinical commitment $(p<0.001)$. When the significant variables were entered into a multivariate analysis, the results showed that dissatisfaction was associated with wanting to change supervisors and with a threat to professional status.

Conclusions: Stress and bullying are common in doctors undertaking research. These findings have important implications for medical training and for doctors choosing research projects. Setting up systems of support may have important benefits.
A lthough it is difficult to define accurately, stress appears to be an unavoidable and common aspect of a doctor's work. ${ }^{1-3}$ It may have positive aspects in that some individuals may feel challenged and may be able to raise productivity to meet increasing demands ${ }^{4}$; however, in junior doctors, work related stress and anxiety have been shown to lead to low morale and poorer work performance and to adversely affect the quality of care provided. ${ }^{156}$

A number of studies have shown that one specific stressor, workplace bullying, is frequently experienced by junior doctors and leads to reduced job satisfaction, depression and anxiety, sickness absence, and intention to leave..$^{27-9}$ The problem has however been difficult to study because individual responses to stressful situations vary and certain people are more likely than others to perceive high levels of stress in their jobs. ${ }^{411} 11$ In addition to this, there is no generally accepted definition of workplace bullying, although it appears to refer to situations in which someone is subjected to social isolation or exclusion, his or her work and efforts are devalued, and he or she is frustrated, often threatened, and perhaps even abused. ${ }^{12-14}$ Stress and bullying may lead to poor health, and this may in turn result in an increased susceptibility to becoming a victim of bullying.

Personality factors, particularly negative affectivity, have also been shown to be related to stress, anxiety, and other occupational health outcomes in different areas of medicine, ${ }^{15-18}$ and these factors may contribute to feelings of job dissatisfaction and stress. While many studies have addressed these issues in many different groups of healthcare workers including those at junior, middle grade, and senior staff levels, ${ }^{10}{ }^{19-22}$ none have examined the experience of doctors who are undertaking research. As postgraduate research is becoming a commonplace activity (and requirement) among physicians of all specialties in the United Kingdom, ${ }^{23-28}$ we attempted, for the first time, to assess levels of stress and bullying in these physicians.

\section{METHODS}

A questionnaire was posted on the home page of an internet website. It was aimed at doctors who had stated that they were undertaking research after registering their personal information with www.doctors.net.uk, the largest website for doctors in Europe. Participation was voluntary and anonymous, and participants were prevented from completing the questionnaire twice by electronic coding. The questionnaire collected demographic and job related information and then asked participants a number of questions related to the funding of research and writing up, their relationships with supervisors and colleagues, and their perceptions of support, isolation, and overwork. Finally participants were asked about their experiences of the four major categories of bullying behaviour: threat to professional status; threat to personal standing; isolation; and enforced overwork.

Threat to professional status was defined as exposure to the following: belittling opinion, unjustified criticism and monitoring of work, public humiliation, and intimidatory use of disciplinary procedures. Threat to personal standing included teasing, insults, name-calling, sarcasm, and verbal and non-verbal threats. Isolation included withholding necessary information, freezing out, ignoring or excluding, and unreasonable refusal of applications for leave, training, or promotion. Enforced overwork was defined as undue pressure to produce work and the setting of impossible deadlines. ${ }^{8}$ All those who completed the questionnaire answered all questions.

Data were analysed using $\chi^{2}$ test statistics; a univariate logistic regression method was used to estimate the likelihood of dissatisfaction based on whether participants would recommend their research post to a colleague. Those variables that were found to be significant in univariate models $(\mathrm{p}<0.15)$ were selected to build a multivariate model, and those variables that were found to be co-correlated with other variables were left in the model to adjust for residual 


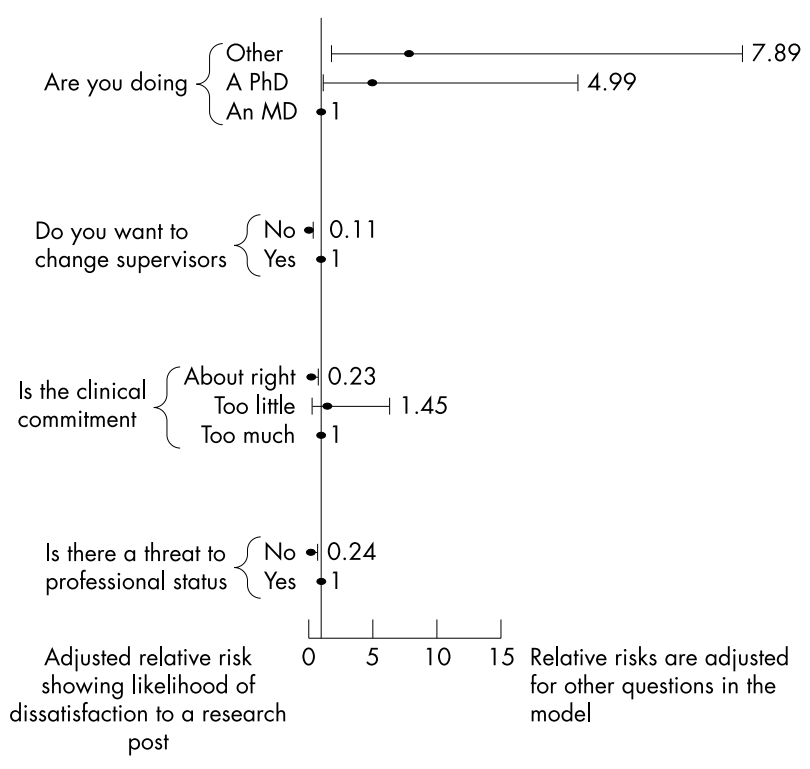

Figure 1 Multivariate logistic regression model showing significant independent predictors of dissatisfaction with a research post. Relative risks ( $x$ axis) are adjusted for all other variables in the model. Error bars represent $95 \%$ confidence intervals.

confounding. The multivariate model with the strongest statistical and clinical consistency is presented and shows significant independent predictors of dissatisfaction after adjusting for all other variables in the model (fig 1). All p values presented are two sided.

\section{RESULTS AND DISCUSSION}

Participants were predominantly male $(\mathrm{n}=175 ; 68 \%)$ white $(\mathrm{n}=181 ; 70 \%)$ specialist registrars $(\mathrm{n}=148 ; 57 \%)$ undertaking an $\mathrm{MD}(\mathrm{n}=143 ; 55 \%)$. A smaller proportion were undertaking a $\mathrm{PhD}(\mathrm{n}=65 ; 25 \%) ;$ only $22 \%$ of the participants $(n=56)$ reported that they were undertaking the research because of a genuine interest, and only four individuals who answered this survey were black (table 1).

Research funding came from a grant in $44 \%$ of cases $(n=113)$, from a pharmaceutical company in $10 \%(n=27)$, and was arranged entirely by the supervisor in $46 \%$ of cases $(n=119)$. Overall, $53 \%$ of respondents were from medical specialties (including paediatrics) and 29\% from surgical specialties (including accident and emergency, ophthalmology, and otolaryngology); $7 \%$ were psychiatrists, $7 \%$ were obstetricians and gynaecologists, and $4 \%$ were anaesthetists.

One hundred and sixty participants $(62 \%)$ reported that they would recommend their research post to a colleague. Univariate analysis showed significant correlations $(\mathrm{p}<0.001)$ between the $38 \% \quad(\mathrm{n}=99)$ who would not recommend their post and those who reported experiencing stress and bullying (table 1). Doctors who reported that they would not recommend their research post were more likely to have poor relationships with their supervisors, to want to change them and to have inadequate clinical commitment. They were also more likely to report all four categories of bullying behaviour. There was no statistically significant correlation between dissatisfaction and whether doctors were in "medical" or "surgical" specialties.

The number of physicians undertaking research who were not prepared to recommend their research post to a colleague was used as a measure of job dissatisfaction in the logistic regression analysis. The multivariate model shows that doctors who are undertaking a $\mathrm{PhD}$ are more likely to be dissatisfied than are those who are undertaking an MD $(p=0.03)$ (fig 1). Dissatisfaction was further independently associated with wanting to change supervisor $(p=0.001)$ and a threat to professional status $(p=0.01)$. Doctors with an "about right" clinical commitment were significantly less likely to be dissatisfied $(\mathrm{p}=0.02)$.

Though the need to help doctors, particularly junior ones, to manage stress is widely recognised, it is usually considered that the stress is caused by the working conditions, which entail long hours of work, disruption of sleeping patterns, and dealing with seriously ill people. ${ }^{13429}$ A further issue highlighted is that doctors feel particularly stressed when they feel that their competence has been exceeded, although, encouragingly, stress does not appear to be related to impaired mental health. ${ }^{30}$

This study, the first of its kind, suggests that even in the research environment doctors do not escape stress. Levels of job dissatisfaction, isolation, and bullying among doctors holding research posts are unacceptably high. Our survey (table 1) showed that more than a third would not recommend their post to a colleague. Of these, over half had experienced bullying in the form of threats to their professional status and personal standing, and had felt overworked and unsupported, while two thirds felt isolated. In the multivariate analysis, job dissatisfaction was found to be associated with a threat to professional status, which included intimidation and humiliation at work, after controlling and stratifying for other factors in the model. This study is however limited by several factors, including high correlations between different questions, the lack of a control group or comparable group either within medicine and analysis of those who were "satisfied"; further questionnaires should be designed to overcome this. These could consider questions of autonomy and lack of congruence between workload and responsibility, and, importantly, should include as a control group scientists who are not physicians. They may also wish to address the question of the disincentives to undertake research, for example the reported disparity in pay compared with colleagues providing only a clinical commitment. ${ }^{31}$

In recent years, efforts have been made to improve working conditions and training for doctors, and stress counselling is becoming commonplace. Several European countries, including England, Sweden, Norway, and Finland, have taken general preventative action against workplace bullying. This has taken the form of, for example, efforts to increase public awareness, funding for research into stress and bullying, and the establishment of protective legislation. ${ }^{32}$ A reduction in bullying is not only likely to help those being bullied and suffering stress but also brings economic and other benefits to employers. ${ }^{73}$

Work related stress can affect doctors' health and result in poor morale and motivation, poor communication and decision making, and poor relationships with colleagues. It also has financial implications through doctors taking sick leave or ceasing to practise medicine. ${ }^{4}{ }^{34}$ Providing a more supportive work environment with appropriate attention to workloads and the provision of guidelines illustrating good practice in supervision may help to protect the health of medical staff doing research. Interestingly, teachers who take a course in human relations appear to suffer less stress, ${ }^{35}$ although the relationship between a relatively new position (in this case a physician undertaking research) and stress is poorly understood.

Doctors contemplating research may wish to choose less stressful appointments on the basis of these findings, for example by undertaking an $\mathrm{MD}$ as opposed to a $\mathrm{PhD}$ and by ensuring an "about right" clinical commitment. This is consistent with evidence suggesting that a well conducted and supervised short project may be better for a doctor's 
Table 1 Univariate logistic regression model showing the likelihood of dissatisfaction with a research post as indicated by a no response to "would you recommend your research post to a colleague". Reference category is indicated by a relative risk of one

\begin{tabular}{|c|c|c|c|c|}
\hline & \multicolumn{2}{|c|}{$\begin{array}{l}\text { Would you recommend your research post to a } \\
\text { colleague? }\end{array}$} & \multirow{2}{*}{$\begin{array}{l}\text { Likelihood of dissatisfaction: } \\
\text { relative risk ( } 95 \% \text { confidence } \\
\text { interval) }\end{array}$} & \multirow[b]{2}{*}{ Likelihood ratio ( $\mathrm{p}$ value) } \\
\hline & $\begin{array}{l}\text { Yes }(n=160): \text { job } \\
\text { satisfaction }\end{array}$ & $\begin{array}{l}\text { No }(n=99) \text { : job } \\
\text { dissatisfaction }\end{array}$ & & \\
\hline \multicolumn{5}{|l|}{ Demographic information } \\
\hline \multicolumn{5}{|l|}{ Have you completed or are you doing } \\
\hline A PhD & 43 & 22 & 0.95 (0.51 to 1.77 ) & \\
\hline An MD & 93 & 50 & 1 & 0.057 \\
\hline \multirow{2}{*}{\multicolumn{5}{|c|}{ Did you do this as }} \\
\hline & & & & \\
\hline A genuine interest & 40 & 16 & $0.29(0.13$ to 0.64$)$ & \\
\hline A means to an end & 24 & 33 & 1 & 0.002 \\
\hline \multirow{2}{*}{\multicolumn{5}{|c|}{ Gender }} \\
\hline & & & & \\
\hline Male & 103 & 72 & 1 & 0.160 \\
\hline Female & 57 & 27 & 0.68 (0.39 to 1.17$)$ & \\
\hline \multicolumn{5}{|l|}{ What is your grade? } \\
\hline Senior house officer & 39 & 30 & $1.13(0.52$ to 2.46$)$ & \\
\hline Specialist registrar & 96 & 52 & $0.80(0.39$ to 1.61$)$ & 0.475 \\
\hline Other & 25 & 17 & $1+6$ & \\
\hline \multicolumn{5}{|l|}{ Ethnicity } \\
\hline Blacḱ & 3 & 1 & 0.55 (0.06 to 5.43$)$ & \\
\hline White & 113 & 68 & 1 & 0.840 \\
\hline Indian & 28 & 21 & 1.25 (0.66 to 2.37$)$ & \\
\hline \multirow{2}{*}{\multicolumn{5}{|c|}{ Was the research funding }} \\
\hline & & & & \\
\hline From a grant & 76 & 37 & 0.52 (0.22 to 1.23$)$ & \\
\hline From a pharmaceutical company & 14 & 13 & & 0.223 \\
\hline Arranged by your supervisor & 70 & 49 & 0.75 (0.33 to 1.74$)$ & \\
\hline \multicolumn{5}{|l|}{ Stressors } \\
\hline Was funding difficult to arrange? & & & & \\
\hline Yes & 54 & 50 & 1 & $<0.001$ \\
\hline No & 89 & 26 & $0.32(0.18$ to 0.56$)$ & \\
\hline Don't know & 17 & 23 & $1.46(0.70$ to 3.05$)$ & \\
\hline Do you worry about money? & & & & \\
\hline Yes & 69 & 67 & 1 & $<0.001$ \\
\hline Not really & 47 & 19 & $0.42(0.22$ to 0.78$)$ & \\
\hline No & 44 & 13 & $0.30(0.15$ to 0.62$)$ & \\
\hline Do you want to change supervisor? & & & & \\
\hline Yes & 26 & 74 & 1 & $<0.001$ \\
\hline No & 134 & 25 & 0.07 (0.04 to 0.12 ) & \\
\hline Does your supervisor listen to you? & & & & \\
\hline Yes & 159 & 64 & Unstable owing to small numbers & \\
\hline No & 1 & 35 & & \\
\hline Is the information given by your supe & visor consistent? & & & \\
\hline Yes & 151 & 44 & 1 & $<0.001$ \\
\hline No & 9 & 55 & $21.0(9.6$ to 45.8$)$ & \\
\hline Are your colleagues helpful? & & & & \\
\hline Yes & 156 & 77 & 1 & $<0.001$ \\
\hline No & 4 & 22 & 11.1 (3.7 to 33.5 ) & \\
\hline Is your clinical commitment & & & & \\
\hline Too little? & 20 & 32 & 1.51 (0.73 to 3.13$)$ & \\
\hline Too much? & 35 & 37 & & $<0.001$ \\
\hline About right? & 105 & 30 & $0.27(0.15$ to 0.50$)$ & \\
\hline Are you worried about writing up? & & & & \\
\hline Yes & 99 & 81 & $0.36(0.20$ to 0.66$)$ & $<0.001$ \\
\hline No & 61 & 18 & 1 & \\
\hline Bullying & & & & \\
\hline Have you experienced a threat to yo & I professional status? & & & \\
\hline Yes & 41 & 71 & 1 & $<0.001$ \\
\hline No & 119 & 28 & 0.14 (0.08 to 0.24$)$ & \\
\hline Have you experienced a threat to yo & r personal standing? & & & \\
\hline Yes & 34 & 74 & 1 & $<0.001$ \\
\hline No & 126 & 25 & $0.09(0.05$ to 0.16$)$ & \\
\hline Do you feel isolated? & & & & \\
\hline Yes & 105 & 89 & 1 & $<0.001$ \\
\hline No & 55 & 10 & $0.21(0.1$ to 0.45$)$ & \\
\hline Do you feel overworked? & & & & \\
\hline Yes & 76 & 74 & 1 & $<0.001$ \\
\hline No & 84 & 25 & $0.31(0.18$ to 0.53$)$ & \\
\hline Do you feel supported? & & & & \\
\hline Yes & 159 & 37 & Unstable owing to small numbers & \\
\hline No & 1 & 62 & & \\
\hline
\end{tabular}


career than longer periods in research. ${ }^{36}$ An increased awareness of the problems faced by doctors undertaking research may also help to alleviate the problems faced. It is time to move away from a professional culture that accepts and expects that stress and bullyinig is inevitable, and to concentrate on improving the working conditions for all in our profession.

\section{ACKNOWLEDGEMENTS}

We are extremely grateful to Rebecca Small and Tim Ringrose at www.doctors.net.uk for posting this survey on their internet site.

JS would like to acknowledge the support of Frances Gotch, Steve Patterson, Don Henderson, Mark Nelson, and Brian Gazzard.

There was no external funding for this project.

\section{Authors' affiliations}

J Stebbing, S Mandalia, S Portsmouth, J Crane, M Bower, Chelsea and Westminster Hospital, London, UK

P Leonard, Department of Oncology, Southend Hospital, Westcliff-onSea, Essex, UK

H Earl, Department of Oncology, Addenbrooke's Hospital, University of Cambridge, Cambridge, UK

L Quine, Centre for Research in Health Behaviour, Department of Psychology, Keynes College, University of Kent at Canterbury, Canterbury, UK

\section{REFERENCES}

1 Hsu K, Marshall V. Prevalence of depression and distress in a large sample of Canadian residents, interns, and fellows. Am J Psychiatry 1987; 144:1561-6.

2 Daugherty SR, Baldwin DC Jr, Rowley BD. Learning, satisfaction, and mistreatment during medical internship: a national survey of working conditions. JAMA 1998;279:1194-9.

3 Stebbing J. Stress in health professionals. J R Soc Med 2000;93:208-10.

4 Newbury-Birch D, Kamali F. Psychological stress, anxiety, depression, job satisfaction, and personality characteristics in preregistration house officers. Postgrad Med J 2001:77:109-11.

5 Frank E, McMurray JE, Linzer M, et al. Career satisfaction of US women physicians: results from the Women Physicians' Health Study. Society of General Internal Medicine Career Satisfaction Study Group. Arch Intern Med 1999; 159:1417-26.

6 Firth-Cozens J, Mowbray D. Leadership and the quality of care. Qual Health Care 2001;10(suppl 2):ii3-7.

7 Kivimaki M, Elovainio M, Vahtera J. Workplace bullying and sickness absence in hospital staff. Occup Environ Med 2000;57:656-60.

8 Quine L. Workplace bullying in NHS community trust: staff questionnaire survey. BMJ 1999;318:228-32.

9 Quine L. Workplace bullying in junior doctors: questionnaire survey. BMJ 2002;324:878-9.
10 Firth-Cozens J. Source of stress in women junior house officers. BM 1990;301:89-91.

11 Birch D, Ashton H, Kamali F. Alcohol, drinking, illicit drug use, and stress in junior house officers in north-east England. Lancet 1998;352:785-6.

12 Baldwin DC Jr, Daugherty SR, Rowley BD. Residents' and medical students' reports of sexual harassment and discrimination. Acad Med 1996;71/10 suppl):S25-7.

13 Baldwin DC Jr, Daugherty SR. Do residents also feel "abused"? Perceived mistreatment during internship. Acad Med 1997:72(10 suppl 1):S51-3.

14 Koh TS, Koh TH. Bullying in hospitals. Occup Environ Med 2001;58:610.

15 Sutherland VJ, Cooper CL. Identifying distress among general practitioners: predictors of psychological ill-health and job dissatisfaction. Soc Sci Med 1993:37:575-81.

16 Deary IJ, Blenkin H, Agius RM, et al. Models of job-related stress and personal achievement among consultant doctors. Br J Psychol 1996;87:3-29.

17 Agius RM, Blenkin H, Deary IJ, et al. Survey of perceived stress and work demands of consultant doctors. Occup Environ Med 1996;53:217-24

18 Newbury-Birch D, Lowry RJ, Kamali F. The changing patterns of drinking, illicit drug use, stress, anxiety and depression in dental students in a UK dental school: a longitudinal study. Br Dent J 2002;192:646-9.

19 Sutherland VJ, Cooper CL. Job stress, satisfaction, and mental health among general practitioners before and after introduction of new contract. $B M J$ 1992;304:1545-8.

20 Firth-Cozens J. The five years after qualification. BMJ 1994;309:1524-5.

21 Blenkin H, Deary I, Sadler A, et al. Stress in NHS consultants. BMJ 1995;310:534

22 Firth-Cozens J. Predicting stress in general practitioners: 10 year follow up postal survey. BMJ 1997;315:34-5.

23 The Academic Medicine Group. Academic medicine: problems and solutions. The Academic Medicine Group. BMJ 1989;298:573-9.

24 Schrier RW. Ensuring the survival of the clinician-scientist. Acad Med 1997:72:589-94.

25 Feneley MR, Feneley RC. The contribution of research to urological training in the United Kingdom. Br J Urol 1998;81:193-8.

26 Griffin GE. Careers in academic medicine. J R Coll Physicians Lond 1999:33:468-9.

27 Bateman $\mathrm{H}$, Kinmonth AL. Journeys and pathways: exploring the role of professional development advice and educational guidance for practitioners expressing interest in research. Med Educ 2001;35:49-55

28 Stewart PM. Academic medicine: a faltering engine. BMJ 2002;324:437-8.

29 Buysse DJ, Barzansky B, Dinges D, et al. Sleep, fatigue, and medical training: setting an agenda for optimal learning and patient care. Sleep 2003;26:218-25.

30 Simpson LA, Grant L. Sources and magnitude of job stress among physicians. $J$ Behav Med 1991;14:27-42.

31 Goldacre M. Stear S, Richards R, et al. Junior doctors' views about careers in academic medicine. Med Educ 1999;33:318-26.

32 Vartia $M$. The sources of bullying: psychological work environment and organizational climate. Eur J Work Organisational Psychol 1996:5:203-14.

33 Sibbald B, Enzer I, Cooper C, et al. GP job satisfaction in 1987, 1990 and 1998: lessons for the future? Fam Pract 2000;17:364-71.

34 Quine L. Effects of stress in an NHS trust: a study. Nurs Stand 1998;13:36-41.

35 Rutter H, Herzberg J, Paice E. Stress in doctors and dentists who teach. Med Educ 2002;36:543-9.

36 Vohra HA. The other option in research. J R Coll Surg Edinb 2001;46:340. 